\title{
Antibodies specific for a segment of human membrane IgE deplete IgE-producing B cells in humanized mice
}

\author{
Hans D. Brightbill,, ${ }^{1}$ Surinder Jeet, ${ }^{1}$ Zhonghua Lin, ${ }^{1}$ Donghong Yan, ${ }^{1}$ Meijuan Zhou, ${ }^{1}$ Martha Tan, ${ }^{2}$ \\ Allen Nguyen, ${ }^{2}$ Sherry Yeh, ${ }^{2}$ Donnie Delarosa, ${ }^{2}$ Steven R. Leong, ${ }^{1}$ Terence Wong, ${ }^{3}$ Yvonne Chen, ${ }^{3}$ \\ Mark Ultsch, ${ }^{4}$ Elizabeth Luis, ${ }^{5}$ Sree Ranjani Ramani, ${ }^{5}$ Janet Jackman, ${ }^{1}$ Lino Gonzalez, ${ }^{5}$ \\ Mark S. Dennis, ${ }^{3}$ Anan Chuntharapai, ${ }^{3}$ Laura DeForge, ${ }^{2}$ Y. Gloria Meng, ${ }^{2}$ Min Xu, ${ }^{1}$ \\ Charles Eigenbrot, ${ }^{4}$ Wyne P. Lee, ${ }^{1}$ Canio J. Refino, ${ }^{1}$ Mercedesz Balazs, ${ }^{1}$ and Lawren C. Wu ${ }^{1}$
}

1Department of Immunology, ${ }^{2}$ Department of Assay and Automation Technology, ${ }^{3}$ Department of Antibody Engineering, ${ }^{4}$ Department of Protein Engineering, and ${ }^{5}$ Department of Protein Chemistry, Genentech Inc., South San Francisco, California, USA.

\begin{abstract}
IgE-mediated hypersensitivity is central to the pathogenesis of asthma and other allergic diseases. Although neutralization of serum IgE with IgE-specific antibodies is in general an efficacious treatment for allergic asthma, one limitation of this approach is its lack of effect on IgE production. Here, we have developed a strategy to disrupt IgE production by generating monoclonal antibodies that target a segment of membrane IgE on human IgE-switched B cells that is not present in serum IgE. This segment is known as the M1' domain, and using genetically modified mice that contain the human M1' domain inserted into the mouse $I g E$ locus, we demonstrated that M1'-specific antibodies reduced serum IgE and IgE-producing plasma cells in vivo, without affecting other immunoglobulin isotypes. M1'-specific antibodies were effective when delivered prophylactically and therapeutically in mouse models of immunization, allergic asthma, and Nippostrongylus brasiliensis infection, likely by inducing apoptosis of IgE-producing B cells. In addition, we generated a humanized M1'-specific antibody that was active on primary human cells in vivo, as determined by its reduction of serum IgE levels and IgE plasma cell numbers in a human PBMC-SCID mouse model. Thus, targeting of human IgE-producing B cells with apoptosis-inducing $\mathrm{M1}^{\prime}$-specific antibodies may be a novel treatment for asthma and allergy.
\end{abstract}

\section{Introduction}

Elevated serum IgE levels and IgE-mediated hypersensitivity are central to the pathogenesis of atopic diseases such as allergic asthma (1-4). Elevated serum IgE levels cause the upregulation of IgE receptors on mast cells and basophils, increase the sensitivity of these cells to allergen-triggered activation, and also enhance cell survival $(5,6)$. Therapeutic targeting of serum IgE with a neutralizing, non-anaphylactogenic IgE-specific antibody is an efficacious treatment for moderate-to-severe allergic asthma (7-9). Neutralization of serum IgE with this IgE-specific antibody desensitizes mast cells and basophils by decreasing surface IgE receptor expression, ultimately leading to decreased exacerbations in asthmatics (10-14). Although efficacious, current therapeutic IgE-specific antibodies do not appear to affect $\operatorname{IgE}$ production $(15,16)$ and therefore must be given frequently and chronically in order to maintain sufficient suppression of serum IgE. In addition, given the need to suppress free serum IgE levels to extremely low levels in order to achieve clinical efficacy, patients with very high levels of baseline IgE are excluded from anti-IgE treatment because of an inability to deliver sufficient amounts of therapeutic antibody.

Crosslinking of the $\mathrm{B}$ cell receptor (BCR) in the absence of additional costimulatory signals can lead to B cell apoptosis (17-28). Apoptotic depletion of B cells through BCR crosslinking has been

Conflict of interest: All authors are employed by Genentech Inc. and hold equity in the Roche Group. In addition, the research in this manuscript was fully funded by Genentech Inc.

Citation for this article: J Clin Invest. 2010;120(6):2218-2229. doi:10.1172/JCI40141. extensively described for immature B cells as a mechanism by which autoreactive $B$ cells are removed from the $B$ cell repertoire. In addition, depletion of naive mature $\mathrm{B}$ cells can be achieved by crosslinking the BCR, using anti-IgM BCR antibodies or BCR superantigens. However, few studies have examined the potential to deplete isotype-switched or memory B cells through BCR crosslinking. Two groups have found that perinatal immunization of mice with IgE, prior to the endogenous production of IgE, results in an IgE-specific antibody response that subsequently inhibits the generation of serum IgE in adult mice $(29,30)$. However, immunization of adult mice is not effective due to the development of tolerance against IgE. Nisonoff and coworkers demonstrated that prophylactic passive transfer of syngeneic IgE-specific antibodies could inhibit primary and memory IgE responses and reduce numbers of IgE-producing cells in adult mice by an unknown mechanism (31). More recently, Achatz and coworkers have demonstrated that antibodies against a membrane-proximal region of the mouse IgE BCR can reduce a primary IgE immune response but do not affect established IgE levels when administered therapeutically (32).

Like other immunoglobulin isotypes, IgE is found in 2 forms, a secreted serum immunoglobulin form and a membrane BCR form, which comprise distinct mRNA splice variants. As compared with mouse membrane IgE, human membrane IgE contains an additional extracellular 52 -amino acid sequence that has been called M1', me.1, or CemX (33-41). M1' is specific for the IgE isotype, is not found on secreted serum IgE, is highly conserved among primate species, and has been detected in human IgE-switched B cells, IgE plasmablasts, and IgE myelomas. 
A
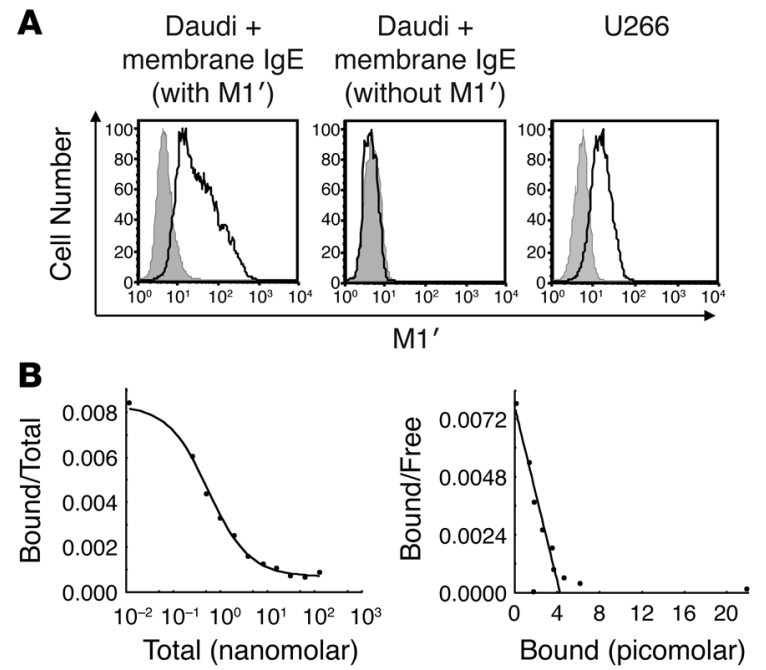

Figure 1

M1'-specific antibody specifically binds human $\mathrm{M1}^{\prime}$ in the context of membrane IgE with high affinity. (A) M1'-specific antibody $47 \mathrm{H} 4$ bound human membrane IgE-transfected Daudi B cells but not Daudi transfectants expressing membrane IgE that lacks the $\mathrm{M} 1$ ' sequence. M1'-specific antibody 47H4 also bound the U266 myeloma cell line, which naturally expresses low levels of membrane IgE. Isotype control antibody staining is shown as the gray areas, and $47 \mathrm{H} 4$ antibody staining is shown as black lines. (B) Scatchard analysis of M1'-specific antibody $47 \mathrm{H} 4$ binding to membrane IgE-transfected Daudi cells. The left panel shows a competition binding curve, where each data point represents the ratio of iodinated $47 \mathrm{H} 4$ antibody bound to cells/total iodinated and unlabeled $47 \mathrm{H} 4$ antibody on the $y$ axis vs. the total concentration of iodinated and unlabeled $47 \mathrm{H} 4$ antibody on the $x$ axis. The right panel shows a Scatchard plot, where each data point represents the ratio of iodinated $47 \mathrm{H} 4$ antibody bound to cells/unbound iodinated $47 \mathrm{H} 4$ antibody on the $y$ axis vs. the concentration of bound iodinated $47 \mathrm{H} 4$ antibody on the $x$ axis The mean binding affinity \pm SD from 2 separate experiments is $0.54 \pm 0.02 \mathrm{nM}$.

Since serum IgE has a very short half-life $(42,43)$, we hypothesized that we could rapidly decrease serum IgE levels by specifically depleting IgE-switched B cells that express membrane IgE. In order to avoid competitive binding of our antibodies to serum IgE as well as anti-IgE-triggered anaphylaxis, we have targeted IgEswitched B cells by generating monoclonal antibodies against the M1' segment of human membrane IgE. We have identified M1'specific antibodies that trigger apoptosis of $\operatorname{IgE} B$ cells by crosslinking the membrane IgE BCR, and we show that an apoptotic $M 1$-specific antibody reduces serum IgE levels and the number of IgE-producing cells in multiple in vivo models when administered either prophylactically or therapeutically. Furthermore, we have generated a humanized M1'-specific antibody that is active on primary human IgE cells in vivo. This humanized M1'-specific antibody may enable a novel therapeutic approach to the treatment of asthma and other allergic diseases.

\section{Results}

Monoclonal M1'-specific antibodies specifically bind human M1'. We generated monoclonal antibodies against the M1' segment of human membrane IgE by immunizing mice with a protein consisting of the $\mathrm{CH} 3, \mathrm{CH} 4$, and $\mathrm{M}^{\prime}$ domains of human IgE fused to the $\mathrm{Fc}$ region of human IgG1, and we then screened for binding to M1'- containing immunogen protein but not to human serum IgE or IgG1. We identified multiple M1'-specific antibodies and selected clone $47 \mathrm{H} 4$ for use in subsequent studies. This $\mathrm{M} 1{ }^{\prime}$-specific antibody binds to Daudi B cell transfectants that express membrane IgE with M1' but not to Daudi transfectants that express a modified membrane IgE lacking M1'. In addition, M1'-specific antibody binds naturally expressed membrane IgE on the U266 myeloma cell line (Figure 1A). M1'-specific antibody binds to membrane IgE Daudi cell transfectants with subnanomolar affinity (Figure 1B).

Generation of human M1' knockin mice. Since mouse membrane IgE lacks an M1' segment, we generated genetically modified mice in which the human M1' segment is inserted immediately after the splice acceptor site of the mouse IgE M1 exon that encodes the transmembrane domain of IgE and which is distal to the exon encoding the $\mathrm{CH} 4$ domain of $\mathrm{IgE}$, thereby mimicking the exact position of $\mathrm{M1}^{\prime}$ in the human IgE locus. In addition, we also inserted a bicistronic GFP reporter gene distal to the last exon of mouse membrane IgE, thereby enabling detection of IgE-switched B cells by GFP fluorescence (Figure 2A and Supplemental Figure 1, $\mathrm{A}$ and $\mathrm{B}$; supplemental material available online with this article; doi:10.1172/JCI40141DS1). M1'/GFP knockin mice were normal, healthy, and fertile, with no alterations in the hematopoietic compartment (data not shown); and the knockin mice had no differences in basal or immunization-induced immunoglobulin isotypes, including $\operatorname{IgE}$, as compared with wild-type mice (Figure 2, $\mathrm{B}$ and $\mathrm{C}$ ). We verified expression of the GFP reporter in vitro, by demonstrating that splenic B cells upregulate GFP expression after 6 days of stimulation with LPS and IL-4, but not LPS alone, concomitant with the generation of serum IgE (Figure 2D). Importantly, M1'-specific antibody binds the in vitro-derived $\mathrm{GFP}^{+}$cells but not $\mathrm{GFP}^{-}$cells. Moreover, we identified a small percentage of $\mathrm{GFP}^{+} \mathrm{B}$ cells in the mesenteric lymph nodes of mice infected with Nippostrongylus brasiliensis (Figure 2E).

$M 1^{\prime}$-specific antibody inhibits primary and memory IgE responses in buman M1' knockin mice. We assessed the ability of M1'-specific antibody to prevent the generation of antigen-specific serum IgE in either a primary or secondary/memory immune response in vivo (Figure 3A). Compared with control antibody treatment, prophylactic treatment with $\mathrm{M} 1$ '-specific antibody reduced the generation of antigen-specific IgE by $99 \%$, upon primary immunization of human M1' knockin mice (Figure 3B). This effect was specific to IgE, as antigen-specific IgG1 was not affected by M1'-specific antibody treatment (Figure 3C). In addition, M1'specific antibody treatment also reduced antigen-specific IgE, but not antigen-specific IgG1, in a secondary/memory immune response (Figure 3, D and E).

$M 1^{\prime}$-specific antibody reduces IgE and depletes IgE-producing cells upon therapeutic treatment of $N$. brasiliensis infection and allergic asthma models. We assessed the effect of therapeutic administration of M1'-specific antibody on serum IgE levels and IgE-producing cells in 2 different models of established, sustained IgE immune responses. Infection of mice with the helminth $N$. brasiliensis induces a robust IgE response (44). Therapeutic treatment of $N$. brasiliensis-infected human M1' knockin mice with M1'-specific antibody at the peak of the $\operatorname{IgE}$ response resulted in a rapid and dramatic reduction in total serum IgE levels (Figure 4, A and B). Total serum IgE levels were reduced by approximately $90 \%$ within 4 days of $\mathrm{M} 1$ '-specific antibody treatment, as compared with those of control antibodytreated mice, and total serum IgE levels reached levels comparable to those of naive unchallenged mice, an approximately 100 -fold 
A

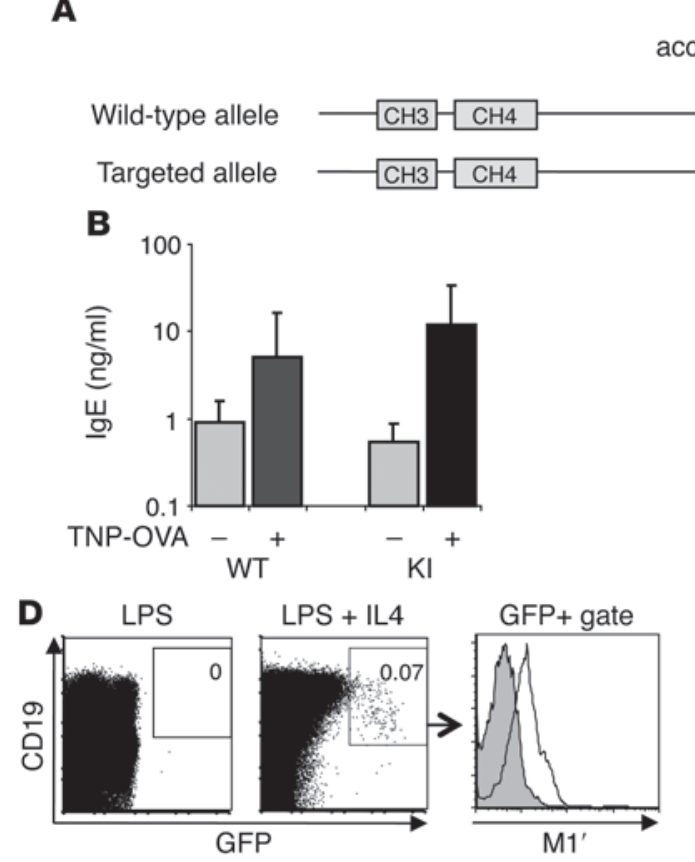

Splice

acceptor site M1 $\mathrm{M} 2$

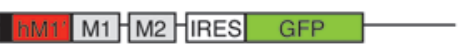

c
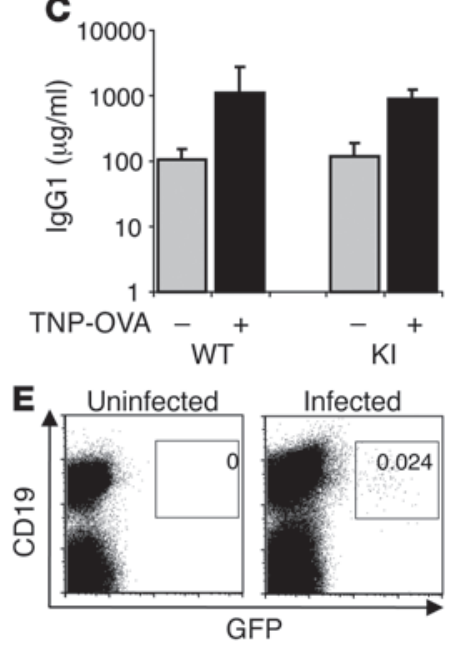

Figure 2

Human M1'/GFP knockin mouse has normal antibody responses and generates M1'+ GFP+ IgE $B$ cells. (A) Targeting scheme for insertion of human $\mathrm{M}^{\prime}$ ' and a bicistronic GFP reporter gene in the mouse IgE locus. Human M1' (red) is inserted into the mouse M1 exon splice acceptor site in-frame, with the M1 exon coding sequence. An IRES-GFP (green) bicistronic reporter gene is inserted 26-bases downstream of the end of the M2 exon. Wild-type and M1' knockin (KI) mice immunized with TNP-OVA/alum have identical baseline and immunization-induced serum (B) IgE and (C) IgG1, as measured by ELISA. (D) Ex vivo culture of M1' knockin mouse splenocytes with LPS and IL-4, but not LPS alone, induced $\mathrm{M1}^{\prime}+\mathrm{GFP}+\mathrm{B}$ cells. Numbers indicate the percentage of $\mathrm{CD} 19+\mathrm{GFP}+$ cells and are representative of at least 3 experiments. Flow cytometry data from LPS+IL-4-stimulated cultures in the center panel was further gated on GFP vs. CD19 expression as defined by the box and analyzed for $\mathrm{M}^{1}$ ' expression as indicated by the arrow to the right-hand panel. Isotype control antibody staining is shown as the gray areas, and $47 \mathrm{H} 4$ antibody staining for $\mathrm{M1}^{\prime}$ ' expression is shown as black lines. (E) A small population of GFP+ $\mathrm{B}$ cells was detectable in the mesenteric lymph nodes of $N$. brasiliensis-infected M1' knockin mice. Numbers indicate the percentage of $\mathrm{CD} 19+\mathrm{GFP}+$ cells and are representative of at least 3 experiments.

decrease, within approximately 10 days. Significantly, reduction of serum IgE levels was accompanied by a decrease in the number of IgE-producing cells in the mesenteric lymph nodes of the M1'-specific antibody-treated mice (Figure 4C). Given that IgE-producing plasma cells constitute an extremely small portion of total immunoglobulin-producing plasma cells, our observation that the total number of plasma cells in the mesenteric lymph nodes was unaffected by M1'-specific antibody treatment (Figure 4D) suggests that M1'-specific antibody does not affect antibody-producing cells of other immunoglobulin isotypes aside from IgE, in agreement with the lack of effect of $\mathrm{M} 1$ '-specific antibody treatment on non-IgE serum immunoglobulins in our other studies.

We also assessed the ability of $\mathrm{M} 1$ '-specific antibody to reduce antigen-specific IgE when delivered therapeutically in a mouse model of allergic asthma (Figure 5A). Human M1' knockin mice were immunized with 2,4,6-trinitrophenyl-conjugated ovalbumin (TNP-OVA) in alum and were subjected to aerosol challenges with TNP-OVA for 7 consecutive days. Therapeutic treatment with M1'-specific antibody was initiated after the fourth aerosol challenge, just prior to the peak of the IgE response. M1'-specific anti- body treatment not only inhibited the generation of additional antigen-specific serum IgE upon additional aerosol challenges with antigen but ultimately decreased antigen-specific serum IgE by approximately 1,000-fold, to levels comparable to those of naive unimmunized mice, within 10 days of treatment (Figure 5B). Antigen-specific IgG1 levels were unaffected by $\mathrm{M} 1$ '-specific antibody treatment (Figure 5C). Similar to therapeutic M1'-specific antibody treatment of $N$. brasiliensis infection, treatment of the allergic asthma model with M1'-specific antibodies reduced the number of IgE-producing plasma cells, although total plasma cell numbers were unaffected (Figure 5, D and E).

$M 1^{\prime}$-specific antibody depletion of IgE lineage $B$ cells is mediated by an apoptotic mechanism. Crosslinking of the BCR can induce apoptosis in primary B cell populations and $\mathrm{B}$ cell lines. We determined the mechanism by which M1'-specific antibody depletes IgE-producing cells by assessing the ability of M1'-specific antibody to induce apoptosis of membrane IgE-transfected Daudi B cells. M1'-specific antibody treatment of membrane IgE Daudi cell transfectants increased the number of annexin $\mathrm{V}^{+}$apoptotic cells in a dose-dependent manner (Figure 6A). The M1'-specific antibody-induced apoptosis was inhibited by the pan-caspase inhibitor z-VAD (Figure 6B) and correlated with the induction of intracellular signaling, as detected by an increase in intracellular calcium flux, induced by $\mathrm{M} 1$ '-specific antibody (Supplemental Figure 2A). The relatively low level of apoptosis induced by M1'-specific antibody may be due to the low level of membrane IgE expression in the Daudi cell transfectants (Supplemental Figure $2 \mathrm{~B}$ ), as the magnitude of the $\mathrm{M} 1^{\prime}$-specific antibody-induced apoptotic response was enhanced by crosslinking of the primary M1'-specific antibody upon addition of an anti-IgG secondary antibody (Supplemental Figure 2C). We were unable to detect any effect of M1'-specific antibody on apoptosis, intracellular calcium flux, or serum IgE production by U266 myeloma cells, which have a very low level of membrane IgE expression (Supplemental Figure 3).

To confirm the in vitro apoptotic activity of $\mathrm{M} 1$ '-specific antibody on primary immune cells, we determined the effect of $M 1^{\prime}$ specific antibody on splenic B cells from M1' knockin mice that were stimulated with anti-CD40 antibody and IL-4 to induce class switching to IgE and the production of soluble IgE. Treatment with $M 1^{\prime}$-specific antibody reduced the frequency of IgE-switched $\mathrm{GFP}^{+} \mathrm{B}$ cells as well as the levels of soluble IgE in the cell culture medium (Figure 6, C and D). These results are comparable with those obtained by Nemazee and coworkers, who used an anti-IgE single chain variable fragment that binds both serum and membrane $\operatorname{IgE}$ in a similar mouse splenocyte culture system (45), and 

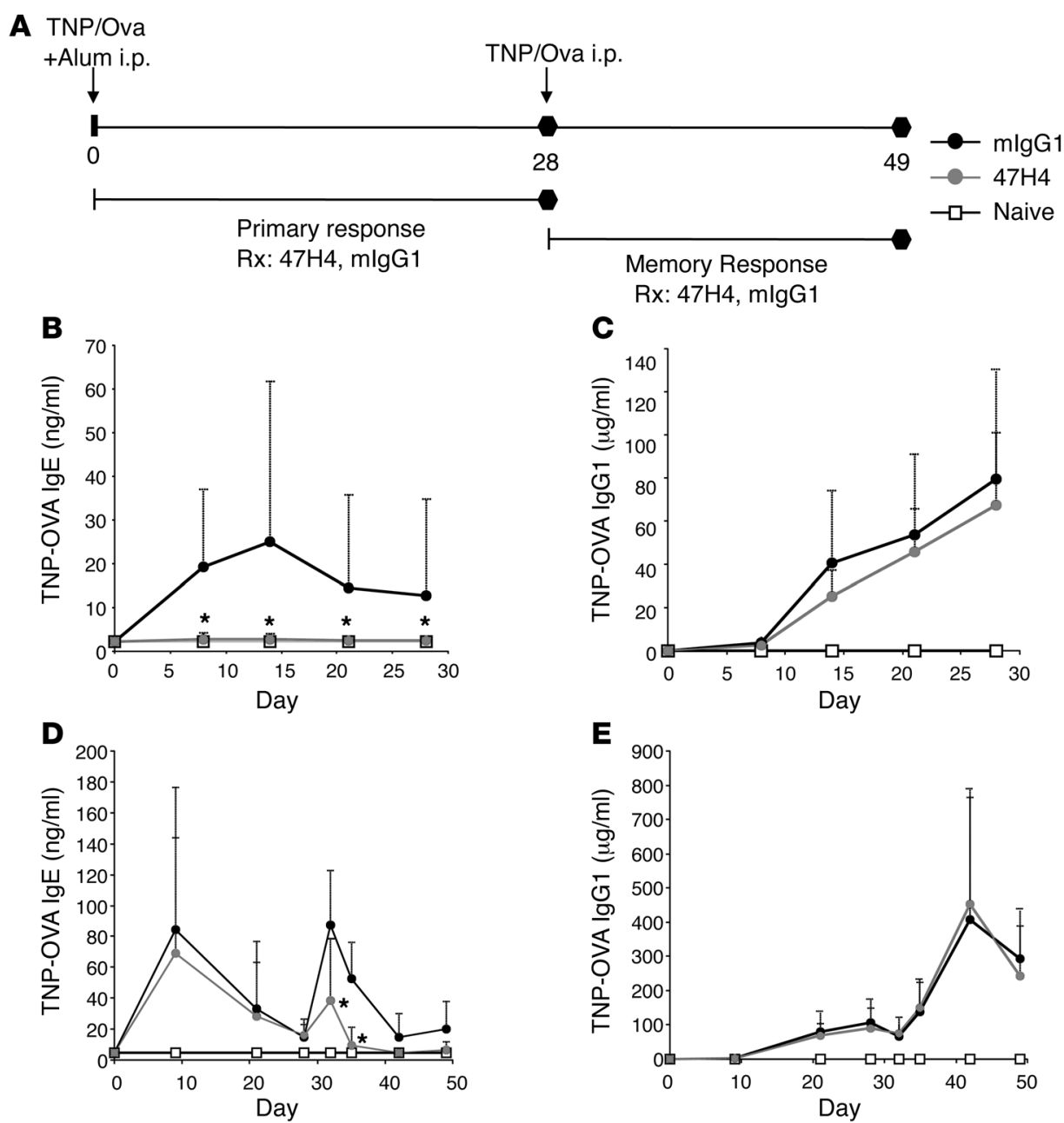

Figure 3

M1'-specific antibody prevents primary and memory $\lg E$ responses in human M1' knockin mice. (A) Experimental design for TNP-OVA-induced primary and memory immune responses. Human M1' knockin mice were immunized with TNP-OVA/alum on day 0 . In the primary $\lg E$ response model ( $n=26$ per group), mice were treated with $10 \mathrm{mg} / \mathrm{kg} \mathrm{M1'-specific} \mathrm{antibody}$ $47 \mathrm{H} 4$ or mlgG1 control antibody 3 times a week from day $0-28$. Treatment with M1'-specific antibody $47 \mathrm{H} 4$ antibody (B) prevented the primary TNP-OVAspecific IgE response, but (C) did not affect the primary TNP-OVA-specific IgG1 response. In the memory IgE response model ( $n=10$ per group), mice were challenged with TNP-OVA alone on day 28 after the primary immunization, and mice were treated with $10 \mathrm{mg} / \mathrm{kg} \mathrm{M1'-specific} \mathrm{antibody}$ $47 \mathrm{H} 4$ or mlgG1 control antibody 3 times a week from day 28-49. Treatment with M1'-specific antibody $47 \mathrm{H} 4$ antibody (D) reduced the memory TNP-OVAspecific IgE response, but (E) did not affect the memory TNP-OVAspecific IgG1 response. Results are mean \pm SD. ${ }^{*} P<0.05$ (Bonferroni correction for pairwise comparisons). are consistent with an apoptotic mechanism, although additional experiments are required to more conclusively demonstrate an apoptotic mechanism in this switch culture system.

To assess whether the in vivo mechanism of M1'-specific antibody treatment is due to apoptotic depletion of IgE-switched B cells, we compared the effects of wild-type $\mathrm{M1}^{\prime}$-specific antibody and an FC effector function-deficient $\mathrm{M} 1^{\prime}$-specific antibody upon treatment of $N$. brasiliensis infection in M1' knockin mice (Figure 6E). We engineered an Fc effector function-deficient M1'-specific antibody by introducing 2 point mutations (D265A and N297A; the resulting antibody is referred to herein as DANA) in the Fc region of the antibody. The DANA antibody lacks Fc effector function, because binding to all $\mathrm{Fc} \gamma$ receptors is abolished, but retains normal in vivo pharmacokinetic properties, because binding to FcRn is unaltered $(46,47)$. Therefore, treatment with the DANA antibody enables assessment of the in vivo apoptotic activity of $\mathrm{M1}^{\prime}$-specific antibody via crosslinking of membrane IgE, independent of Fc-mediated antibody effector functions. Strikingly, both wild-type and DANA M1'-specific antibodies inhibited N. brasiliensis-induced serum IgE to the same extent, with a greater than $90 \%$ reduction of the peak IgE response at day 14 after infection (Figure $6 \mathrm{~F}$ ).

In a separate study, we directly assessed the effects of $M 1^{\prime}$-specific antibody on IgE-switched cells in vivo by detecting IgE-switched $\mathrm{GFP}^{+}$cells in the spleens of $N$. brasiliensis-infected M1' knockin mice. Treatment with $M 1^{\prime}$-specific antibody reduced the frequency of IgE-switched $\mathrm{GFP}^{+} \mathrm{B}$ cells in the spleens of $N$. brasiliensis-infected mice on day 21 (Figure 6, G and $\mathrm{H}$ ), in conjunction with the reduction of the serum IgE response (Supplemental Figure 4A). The remaining $\mathrm{GFP}^{+} \mathrm{B}$ cells that are detected in $\mathrm{M1}^{\prime}$-specific antibodytreated mice may represent newly switched IgE B cells that are in the process of undergoing apoptosis. M1'-specific antibody treatment did not affect the increase in total splenic B cells in N. brasiliensisinfected mice on day 21, which are predominantly IgM and IgG isotypes and therefore not expected to be impacted by M1'-specific antibody treatment that is specific for IgE B cells (Supplemental Figure 4B). Taken together, our studies suggest that apoptosis is the likely mechanism of $\mathrm{M} 1^{\prime}$-specific antibody activity in vivo.

Generation of a bumanized of $M 1^{\prime}$-specific antibody. We generated a humanized $\mathrm{M} 1$ '-specific antibody that is suitable for human therapeutic administration in asthma and other allergic diseases by grafting the murine $\mathrm{M1}^{\prime}$-specific antibody complementary determining regions (CDRs) on to a human IgG1 framework and introducing selected point mutations. The humanized M1'-specific antibody bound to membrane IgE-transfected Daudi cells and U266 cells but not cells transfected with a membrane IgE variant that lacked M1' (Figure 7A) and had low nanomolar affinity for M1', as determined by Biacore (data not shown) and Scatchard binding measurements (Figure 7B). 



\section{Figure 4}

Therapeutic treatment with $\mathrm{M1}$ '-specific antibody specifically reduces IgE in $\mathrm{N}$. brasiliensis infection. (A) Experimental design for therapeutic M1'-specific antibody treatment of $N$. brasiliensis infection. Human M1' knockin mice ( $n=10$ per group) were infected with $500 \mathrm{~N}$. brasiliensis L3 larvae on day 0 . Mice were treated with $10 \mathrm{mg} / \mathrm{kg} \mathrm{M1}$ '-specific antibody $47 \mathrm{H} 4$ or mlgG1 control antibody 3 times per week from day 11 after infection to the end of the study at day 21 after infection. Treatment with M1'-specific antibody $47 \mathrm{H} 4$ antibody reduced (B) total serum IgE levels and (C) the number of IgE-producing cells in the mesenteric lymph nodes, but did not affect (D) the percentage of total syndecan ${ }^{+}$plasma cells in the mesenteric lymph nodes. Results are mean \pm SD. ${ }^{*} P<0.05$ (Bonferroni correction for pairwise comparisons); ${ }^{*} P<0.0001$ (Dunnett's test).

Humanized $M 1^{\prime}$-specific antibody induces apoptosis in vitro and reduces buman serum IgE levels by depleting primary buman IgE B cells in an atopic human PBMC-SCID model. We assessed the apoptotic activity of the humanized M1'-specific antibody in vitro, using membrane IgE-transfected Daudi cells. The humanized M1'-specific antibody induced apoptosis of the Daudi cell transfectants to levels comparable with those induced by murine $\mathrm{M1}^{\prime}$-specific antibody (Figure 8A). To assess the in vivo activity of the humanized M1'-specific antibody on primary human cells, we used an atopic human PBMCSCID mouse model (Figure 8B). Treatment with humanized M1'-specific antibody reduced human IgE levels in the serum by approximately $80 \%$ (Figure $8 \mathrm{C}$ ) and human IgE-producing cells by approximately $75 \%$ (Figure 8D). There was no effect of humanized M1'-specific antibody treatment on human serum IgM (Figure 8E), other immunoglobulin isotypes (data not shown), or the total number of splenic plasma cells (Figure 8F).

A crystal structure of the humanized M1'-specific antibody Fab fragment bound to an M1'-specific antibody-derived peptide suggests that the M1' epitope is largely unstructured. In order to gain insight into the structural basis of M1'-specific antibody binding and activity, we used peptide mapping studies to localize the binding site of the humanized M1'-specific antibody to the N-terminal portion of the M1' sequence (data not shown). We then determined the $\mathrm{x}$-ray crystal structure of the Fab fragment of the humanized M1'-specific antibody in complex with a peptide fragment of the M1' sequence, Ac$S^{6}$ AQSQRAPDRVLCHSGQQQGLPRAAGGSVPHPRCH ${ }^{40}-\mathrm{OOH}$, at $2.4 \AA$ resolution (Figure 9). Only 9 amino acids of the 35 -amino acid peptide were observed in the crystal structure, indicating that the M1'-derived peptide is largely unstructured. Binding of the M1'-specific antibody Fab to the M1' peptide was mediated by several hydrogen bonds, with the side chain of an arginine from the M1' peptide, corresponding to residue 11 of the entire M1' sequence, forming a salt bridge with aspartic acid 99 from the
Fab heavy chain CDRs and inserting into a central deep pocket in the Fab comprised of heavy chain $(\mathrm{H})$ and light chain (L) CDRs L1, L3, and H3 (Figure 9, A and B). Residues from CDRs L2 and H1 did not form important contacts with the peptide, but a total of 7 residues from CDR H2 contacted the peptide, the most of any CDR; and this prominence of CDR $\mathrm{H} 2$ contacts with the M1' peptide was also reflected in the surface area of the Fab that was obscured from solvent by the peptide, when broken down according to $\operatorname{CDR}\left(\sim 190 \AA^{2}, \sim 140 \AA^{2}, \sim 120 \AA^{2}\right.$, and $\sim 110 \AA^{2}$ for CDRs H2, L3, H3, and L1, respectively).

Besides helping form the arginine binding pocket, CDR H3 bears a tryptophan that provided an intimate nonpolar contact with proline 13 of the peptide and which accounts for most of the peptide contacts by CDR H3. The M1' peptide and the Fab each bury approximately $650 \AA^{2}$ of solvent accessible surface in the bound complex, of which $55 \%$ derives from the Fab heavy chain and $45 \%$ from the light chain. The positively charged arginine at the center of the peptide epitope was complemented by a net negative electrostatic potential on the antibody, arising from 4 negatively charged aspartic acid residues that lie in close proximity (Figure 9C). Overall, the relatively long CDR L1 and the major contributions from CDR H2 are hallmarks of antibodies that recognize linear peptide epitopes, in contrast to the shorter L1 and dominant $\mathrm{H} 3$ arrangements that are typical of antibodies that bind tertiary protein structure.

\section{Discussion}

We have generated antibodies that deplete IgE-lineage B cells and reduce serum $\mathrm{IgE}$ by targeting the $\mathrm{M} 1$ ' segment of human membrane IgE. In vivo treatment with $\mathrm{M1}^{\prime}$-specific antibodies significantly reduced serum IgE levels by triggering apoptosis of IgE-switched B cells in multiple models of IgE immune responses, including primary and secondary/memory $\operatorname{IgE}$ immune responses, 

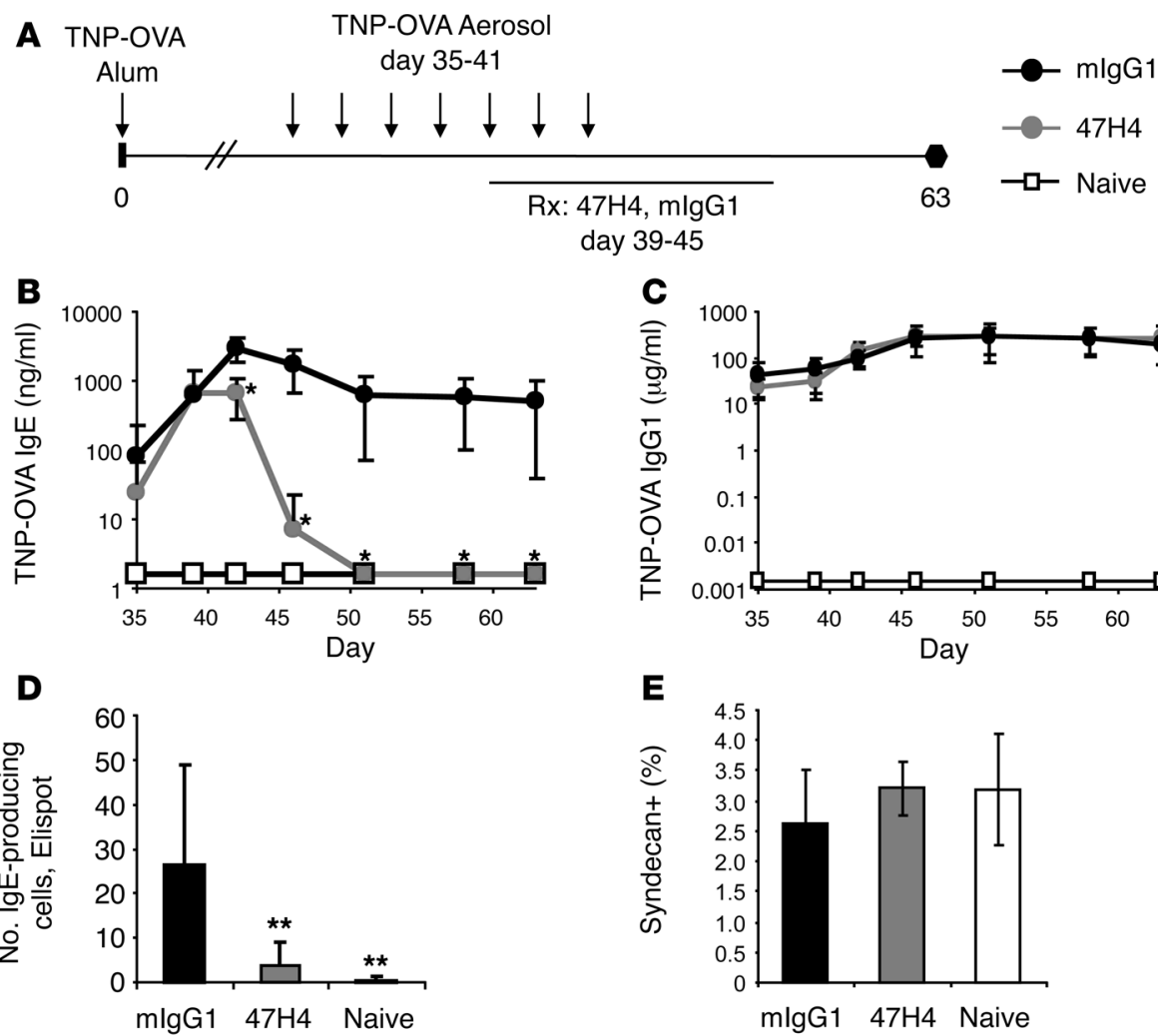

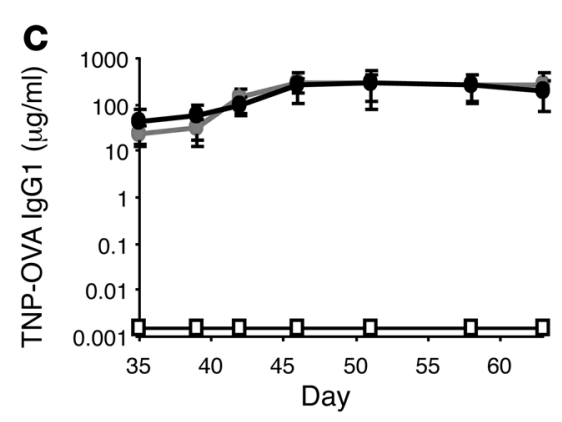

E

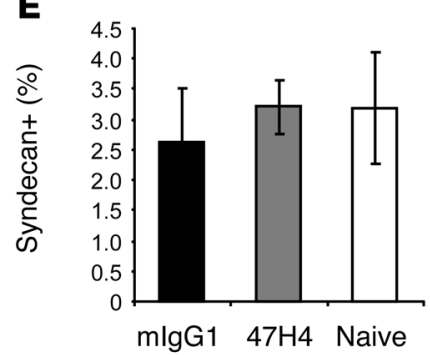

\section{Figure 5}

Therapeutic treatment with $\mathrm{M} 1$ '-specific antibody specifically reduces $\operatorname{IgE}$ in a mouse model of allergic asthma. (A) Experimental design for therapeutic M1'specific antibody treatment of mouse allergic asthma model. Human M1' knockin mice ( $n=8$ per group) were immunized with TNP-OVA/alum on day 0 and challenged with 7 daily aerosol administrations of TNP-OVA, starting on day 35 . Mice were treated with $100 \mu \mathrm{g}$ of M1'specific antibody $47 \mathrm{H} 4$ or control mlgG1 antibody daily from day 39 through day 45. Treatment with M1'-specific antibody 47H4 antibody reduced (B) TNP-OVAspecific IgE levels, but did not affect (C) TNP-OVA-specific IgG1 levels. Treatment with $\mathrm{M} 1$ '-specific antibody $47 \mathrm{H} 4$ antibody also reduced (D) the number of IgE-producing cells, but did not affect (E) the percentage of total syndecan+ plasma cells in the spleen, as measured on day 63. Results are mean $\pm \mathrm{SD}$. ${ }^{\star} P<0.05$ (Bonferroni correction for pairwise comparisons); ${ }^{* *} P<0.05$ (Dunnett's test).
$N$. brasiliensis infection, and allergic asthma. Since M1' is restricted to the membrane form of $\operatorname{IgE}, \mathrm{M} 1$ '-specific antibodies do not bind secreted $\operatorname{IgE}$ or $\operatorname{IgE}$ that is bound to $\operatorname{IgE}$ receptors on mast cells, basophils, and other cells. As such, M1'-specific antibody binding to IgE-switched B cells is not competed by serum IgE, and M1'specific antibodies are non-anaphylactogenic.

Activation of the BCR in the absence of secondary/costimulatory signals can lead to B cell apoptosis (17-28). While multiple studies have demonstrated this effect in immature developing B cells and in mature naive B cells, few studies have investigated whether mature isotype-switched or memory B cells are susceptible to antiBCR-induced apoptosis. Our data indicate that IgE-switched B cells are susceptible to apoptotic depletion by $\mathrm{M} 1^{\prime}$-specific antibodies. In vitro stimulation of human membrane IgE-transfected $\mathrm{B}$ cells with $\mathrm{M1}$ '-specific antibodies induced apoptosis, which was blocked by a caspase inhibitor. In addition, M1'-specific antibody treatment of primary mouse splenocyte cultures reduced the frequency of IgE switching and soluble IgE production. Moreover, in vivo efficacy of $\mathrm{M1}^{\prime}$-specific antibody correlated with a reduction in IgE-switched cells and was independent of antibody Fc effector function, strongly implicating antibody-induced apoptosis as the primary mechanism by which $\mathrm{M} 1$ '-specific antibodies deplete IgEproducing cells and reduce serum IgE. This is in contrast to other $\mathrm{B}$ cell-depleting antibodies, such as anti-CD20 antibodies, which deplete B cells through $\mathrm{F}$ c $\gamma$ receptor-mediated mechanisms such as antibody-dependent cellular cytotoxicity $(48,49)$. Further studies in primary cell culture and in vivo systems may more definitively address the mechanism of $\mathrm{M1}^{\prime}$-specific antibodies.

Importantly, we find that therapeutic delivery of $\mathrm{M} 1$ '-specific antibody in vivo can reduce established IgE responses, as observed in $N$. brasiliensis infection and allergic asthma models.
This is in contrast to studies by Achatz and coworkers, who target mouse IgE B cells using monoclonal antibodies against a membrane-proximal region of the mouse $\operatorname{IgE}$ BCR (32), and who were unable to reduce total or antigen-specific IgE upon therapeutic administration of their antibody. We have found that not all M1'-specific antibodies induce the same degree of apoptosis, as assessed on membrane IgE cell transfectants in vitro, and some M1'-specific antibodies completely lacked apoptotic activity (data not shown). Since we observe that apoptosis is the primary driver of $M 1^{\prime}$-specific antibody efficacy in vivo, antibodies with less intrinsic apoptotic activity may be less effective at reducing IgE levels. The 10-fold difference in affinity and/or the different target epitope between our M1'-specific antibody and the Achatz antibody may result in different amounts of apoptotic activity and the lack of efficacy of the Achatz antibody when administered therapeutically. In this regard, it should be noted that our M1'-specific antibody appears to be more potent than the Achatz antibody, even in reducing a primary IgE immune response. Interestingly, our $x$-ray crystal structure suggests that the first 15 to 20 amino acids of the M1' segment are in an extended or random coil conformation, which may allow optimal access and binding of our M1'-specific antibody to each of the $2 \mathrm{M1}$ ' epitopes that are present on the membrane IgE heavy chain homodimer. Given the close proximity of the M1' segment to the cell membrane and potential spatial constraints on binding of antibody molecules to membrane IgE molecules, it is possible that antibodies that target more $\mathrm{C}$-terminal portions of membrane IgE or other M1' epitopes may not be able to bind and crosslink as many membrane IgE molecules as our M1'-specific antibody, resulting in less efficient formation of apoptosis-inducing highorder multimeric signaling complexes. 


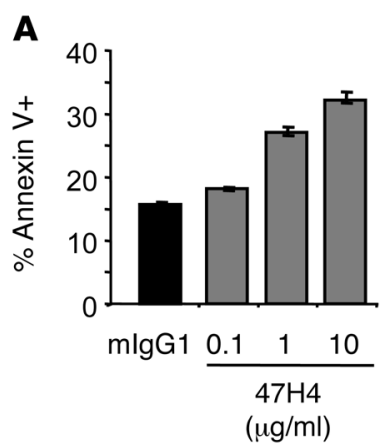

D

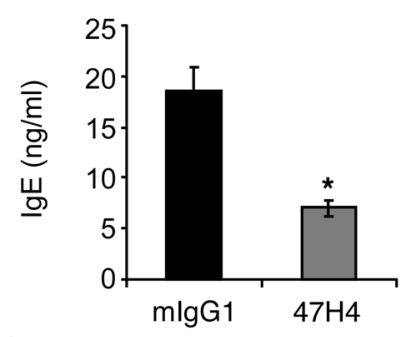

G

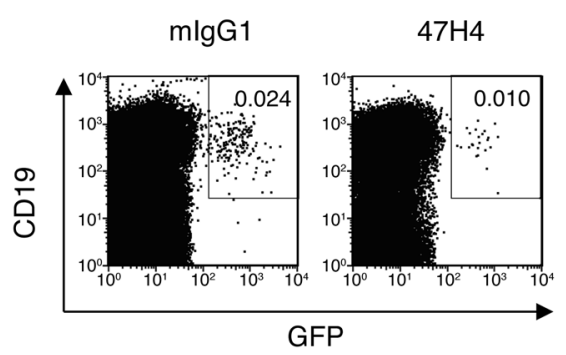

B

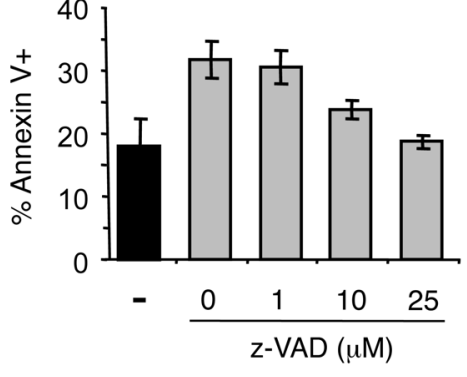

mlgG1 $47 \mathrm{H} 4$

E

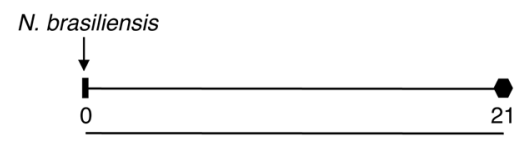

Rx: 47H4-WT, 47H4-DANA, mlgG1

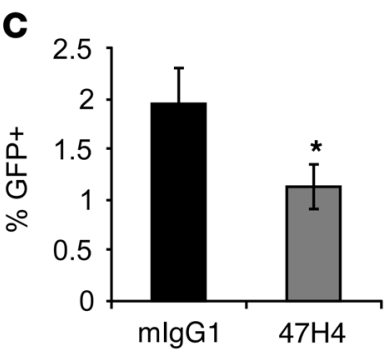

$\mathbf{F}$

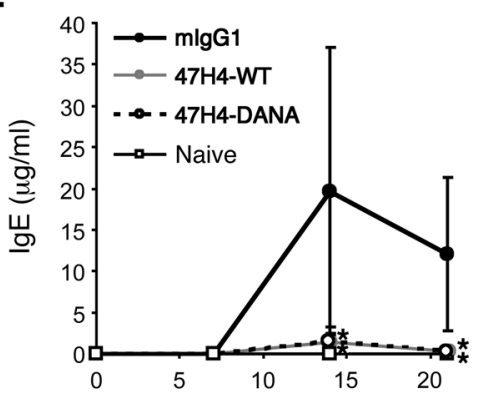

H

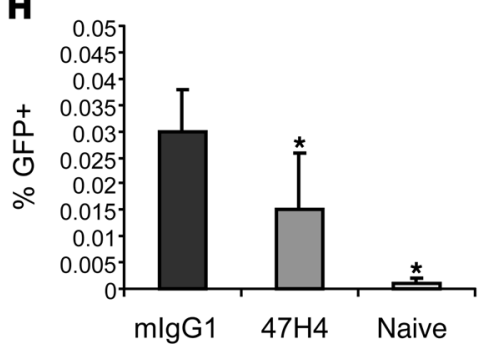

Figure 6

Efficacy of M1'-specific antibody is mediated by apoptosis. (A) M1'-specific antibody $47 \mathrm{H} 4$ antibody induced apoptosis of human membrane lgEtransfected Daudi cells. (B) Caspase inhibitor Z-VAD inhibited M1'-specific antibody $47 \mathrm{H} 4$ antibody-induced apoptosis. Apoptosis is measured by flow cytometry using anti-Annexin $\mathrm{V}$ antibody. The control antibody is mlgG1. (C) M1'-specific antibody $47 \mathrm{H} 4$ antibody reduced the percentage of GFP+ IgE-switched B cells on day 4 in human M1' knockin mouse splenocyte cultures stimulated with anti-CD40 antibody and recombinant IL-4. (D) M1'-specific antibody 47H4 antibody reduced the generation of soluble lgE on day 4 in human M1' knockin mouse splenocyte cultures stimulated with anti-CD40 antibody and recombinant IL-4. (E) Experimental design for M1'-specific antibody treatment of $N$. brasiliensis infection. Human M1' knockin mice ( $n=9-10$ per group) were infected with $500 \mathrm{~N}$. brasiliensis L3 larvae on day 0 . Mice were treated with $10 \mathrm{mg} / \mathrm{kg}$ M1'specific antibody 47H4 wild-type, 47H4-DANA, or mlgG1 control antibody 3 times a week from day 0 to 21 . (F) Treatment with 47H4 wild-type and $47 \mathrm{H} 4-\mathrm{DANA}$ antibody resulted in equivalent inhibition of $N$. brasiliensis-induced serum IgE. Results are mean $\pm \mathrm{SD}$. ${ }^{*} P<0.05$ (Bonferroni correction for pairwise comparisons). (G) Representative flow cytometry plots of IgE-switched GFP+ B cells in the spleens of $N$. brasiliensis-infected mice treated with $\mathrm{M1}^{\prime}$-specific antibody $47 \mathrm{H} 4$ wild-type or mlgG1 control antibody on day 21. Numbers indicate the percentage of CD19+ GFP+ cells and are representative of at least 3 experiments. (H) M1'-specific antibody $47 \mathrm{H} 4$ antibody reduced the percentage of IgE-switched GFP+ $B$ cells in the spleens of $N$. brasiliensis-infected mice on day 21. (A-D and $\mathbf{H})$ Results are mean $\pm \mathrm{SD}$. (C, $\mathbf{D}$, and $\mathbf{H}){ }^{\star} P<0.05$ (Dunnett's test).

We have demonstrated that $\mathrm{M} 1$ '-specific antibody targeting of the IgE B cell lineage can deplete IgE-producing cells and rapidly and significantly reduce serum IgE. Moreover, we have generated a humanized $\mathrm{M1}^{\prime}$-specific antibody that is suitable for administration in human asthma and other allergic diseases. Current anti-IgE therapy consists of non-anaphylactogenic IgE-specific antibody that binds and neutralizes the activity of serum $\operatorname{IgE}(7-9)$. This antibody does not affect IgE production (16) and therefore must be administered frequently and chronically in order to maintain sufficient suppression of free serum IgE. In addition, due to practical constraints on the amount of antibody that can be administered, patients with very high baseline levels of IgE are currently excluded from anti-IgE therapy. Since M1' is not found on serum IgE or IgE that is bound to IgE receptors on mast cells, basophils, and other cells, M1'-specific antibody is non-anaphylactogenic, and treatment with $M 1$ '-specific antibody may not be subject to patient eligibility criteria related to baseline serum IgE levels. As such, M1'-specific antibody targeting of the IgE B cell lineage may be a new approach to the treatment of asthma and other allergic diseases.

Given the ability of M1'-specific antibodies to deplete IgEswitched B cells, it is possible that IgE memory B cells are depleted by $\mathrm{M} 1$ '-specific antibody treatment. The regulation and existence of IgE memory B cells is controversial and poorly understood (50-56). It has been suggested that a significant fraction of $\operatorname{IgE}$ memory 
A Daudi +
membrane IgE
(with $\mathrm{M1} 1^{\prime}$ )

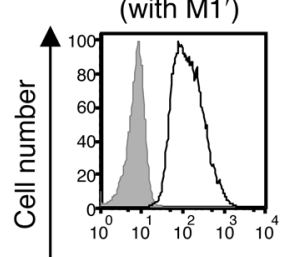

B

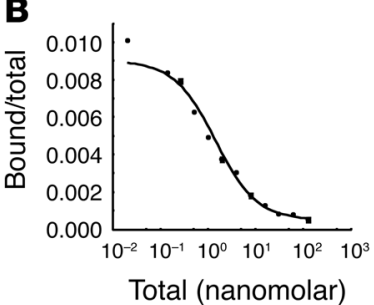

U266 membrane $\lg \mathrm{E}$ (without M1')

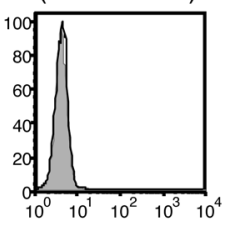

M1'

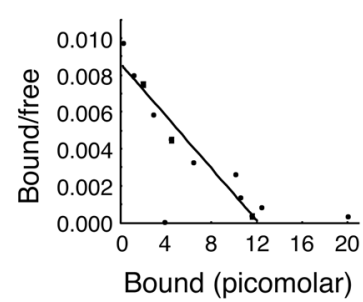

Figure 7

Characterization of a humanized $\mathrm{M} 1^{\prime}$-specific antibody. (A) Humanized $\mathrm{M} 1$ '-specific $47 \mathrm{H} 4$ antibody (h47H4) bound human membrane IgE-transfected Daudi B cells but not Daudi transfectants expressing membrane IgE that lacks the M1' sequence. Humanized M1'-specific 47H4 antibody also bound the U266 myeloma cell line, which naturally expresses low levels of membrane $\mathrm{IgE}$. (B) Scatchard analysis of humanized $\mathrm{M1} 1$-specific $47 \mathrm{H} 4$ antibody binding to membrane IgE-transfected Daudi cells. The left panel shows a competition binding curve, where each data point represents the ratio of iodinated h47H4 antibody bound to cells/total iodinated and unlabeled h47H4 antibody on the $y$ axis vs. the total concentration of iodinated and unlabeled h47H4 antibody on the $x$ axis. The right panel shows a Scatchard plot, where each data point represents the ratio of iodinated $\mathrm{h} 47 \mathrm{H} 4$ antibody bound to cells/unbound iodinated $\mathrm{h} 47 \mathrm{H} 4$ antibody on the $y$ axis vs. the concentration of bound iodinated $\mathrm{h} 47 \mathrm{H} 4$ antibody on the $x$ axis. The mean binding affinity $\pm S D$ from 2 separate experiments is $1.50 \pm 0.14 \mathrm{nM}$.

resides in the IgG1 compartment, with generation of a memory $\mathrm{IgE}$ response resulting from sequential switching of IgG1 memory $\mathrm{B}$ cells to the IgE B cell lineage (50, 54, 57-64). While our studies have not directly addressed this issue, it is interesting that we and others have observed that both primary and memory $\operatorname{IgE}$ responses occur prior to $\operatorname{IgG} 1$ responses in our immunization and asthma models, perhaps indicating that the vast majority of IgE responses do not develop by a sequential switching mechanism through an IgG1 B cell intermediate. In addition, it has also been suggested that, as opposed to other immunoglobulin isotypes, serum IgE derives from short-lived plasma cells, such that serum IgE levels are maintained by a pool of membrane IgE-expressing cells upstream of the plasma cells (65). If IgE memory resides in an IgE memory $\mathrm{B}$ cell compartment that is susceptible to $\mathrm{M} 11^{\prime}$-specific antibodymediated depletion, $\mathrm{M} 1$ '-specific antibody treatment could result in permanent ablation of IgE memory, with long-lasting effects on IgE-mediated diseases. Future studies will address the potential of M1'-specific antibody treatment to abolish IgE memory.

\section{Methods}

Generation of mouse monoclonal M1'-specific antibodies. M1'-specific antibody hybridomas were generated from Balb/c mice (Charles River Laboratories) immunized with a recombinant human IgE/M1' protein, a human IgG1 Fc fusion protein that consists of the $\mathrm{CH} 3$ and $\mathrm{CH} 4$ domains and the first 67

amino acids of the $\mathrm{M1}^{\prime} / \mathrm{M} 1$ domain (NH-GLAGGSAQSQRAPDRVLCHSGQQQGLPRAAGGSVPHPRCHCGAGRADWPGPPELDVCVEEAEGEAPW-OOH) of human membrane IgE fused to human IgG1 Fc. Antibodies were screened by ELISA for the ability to bind the immunogen protein but not human serum IgE or IgG1. Specific binding to M1' was confirmed using Daudi cells that were transfected with membrane IgE, either containing or lacking the M1' segment. Wild-type and effector-deficient D265A/N297A antibodies were cloned from the $47 \mathrm{H} 4$ hybridoma cell line and expressed in $\mathrm{CHO}$ cells. Antibodies were purified by protein A chromatography (proSepA), followed by gel filtration chromatography (S200). Protein identities were confirmed by mass spectrometry and $\mathrm{N}$-terminal sequencing, and endotoxin levels were confirmed to be less than $0.5 \mathrm{EU} / \mathrm{mg}$.

Human M1' knockin mice. Human M1'/GFP knockin mice were generated by targeting the mouse IgE locus with a recombinant DNA replacement vector encoding the human $\mathrm{M1}^{\prime}$ segment inserted immediately after the splice acceptor site of the mouse IgE M1 exon, an internal ribosomal entry site (IRES) element, followed by a GFP reporter gene (a GFP gene with an amino acid change of phenylalanine 64 to leucine) with a $3^{\prime}$ polyadenylation signal inserted 26-bases downstream of the mouse IgE M2 exon, and a neomycin selection cassette flanked by loxP sites. Potential alternative splice acceptor sites created by the human M1' insertion in the mouse M1 exon were removed by introducing point mutations in the human $\mathrm{M} 1$ ' sequence that did not change the protein coding sequence. The targeting vector consisted of $1.9 \mathrm{~kb}$ of the mouse $I g E$ locus upstream of the M1 exon, providing the $5^{\prime}$ arm of homology, and $5.1 \mathrm{~kb}$ of the mouse IgE locus downstream of the M2 exon, providing the $3^{\prime}$ arm of homology. The targeting vector was linearized and electroporated into C57BL/6 ES cells (Taconic). Targeted ES clones were subject to in vitro Cre-mediated removal of the neomycin selection cassette and subsequently injected into B6(Cg)-Tyr ${ }^{\mathrm{r}-2 \mathrm{~J}}$ blastocysts (The Jackson Laboratory) to generate chimeras. Three independent founder lines were identified by PCR genotyping and Southern blot analysis (see Supplemental Methods) and characterized, and one line was selected for use in all subsequent studies. Mice were housed and bred under specific pathogen-free conditions, and all experiments were conducted in accordance with the NIH guidelines for the care and use of mice in research and approved by the Genentech Institutional Animal Care and Use Committee.

Generation of human membrane IgE-expressing cell lines. Membrane IgE-expressing Daudi B cells (ATCC) were generated by retroviral transduction of the parental cells with cDNA encoding the heavy and light chains of human membrane $I g E$, in combination with an internal ribosomal entry sequence, to allow for bicistronic expression of both membrane immunoglobulin chains. Membrane IgE heavy and light chains were subcloned from mRNA derived from the U266 cell line (ATCC) and inserted into the PMSCV retroviral expression vector (BD Clontech). For generation of cell transfectants lacking M1', the membrane IgE heavy chain cDNA was engineered to remove the $\mathrm{M} 1^{\prime}$ segment. Retroviruses were produced using Phoenix packaging cells (G. Nolan, Stanford University, Stanford, California, USA). Surface expression of transfected membrane IgE was determined by flow cytometry, using an antibody against human IgE (MAE11, Genentech), and cells expressing membrane IgE were sorted for use in experiments.

In vitro apoptosis assay. Daudi cells transfected with human membrane IgE were cultured in triplicate in cell culture medium, as recommended by ATCC, with M1'-specific antibody or isotype control antibody for 72 hours in 24-well plates. To assess effects of caspase inhibition on M1'-specific antibody-induced apoptosis, a $50 \mathrm{mM}$ stock solution of z-VAD (Calbiochem) in DMSO was diluted and added to apoptosis cell cultures at a fixed concentration of $0.1 \%$ DMSO in the cell culture medium, in the presence of $25 \mu \mathrm{g} / \mathrm{ml} \mathrm{M1}$ '-specific antibody. Cells were harvested and analyzed by FACS for levels of apoptosis, using the Annexin V-FITC Apoptosis Detec- 
A
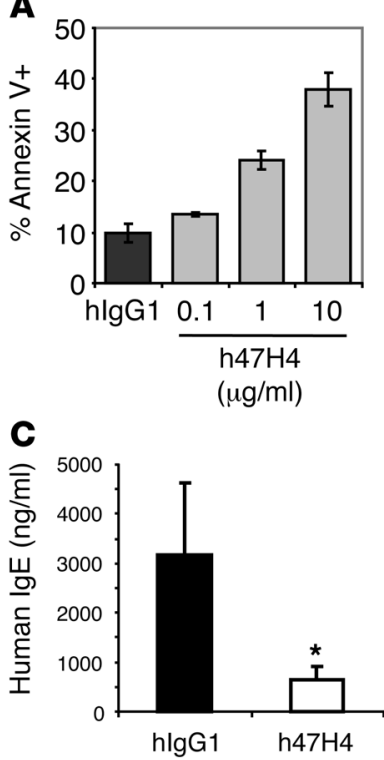

B Human

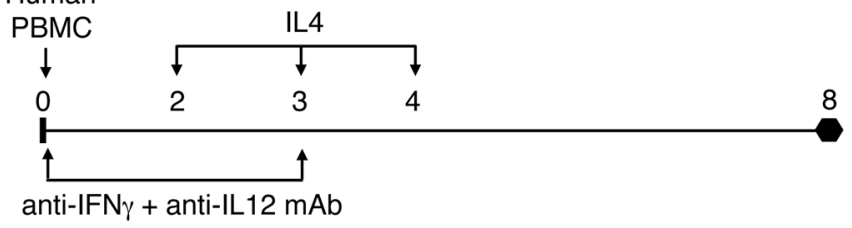

$\mathrm{Rx}: \mathrm{h} 47 \mathrm{H} 4, \mathrm{hlgG} 1$

D

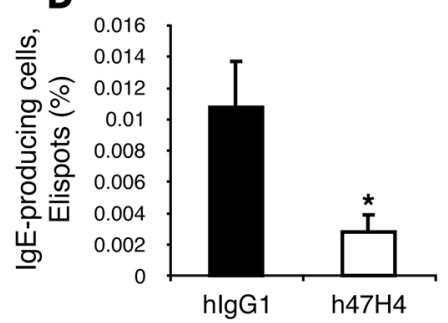

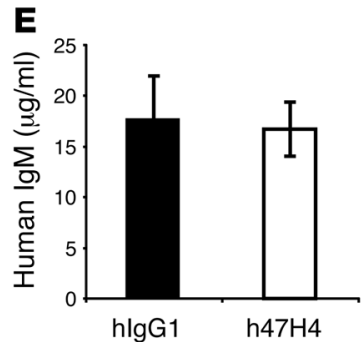

$\mathbf{F}$

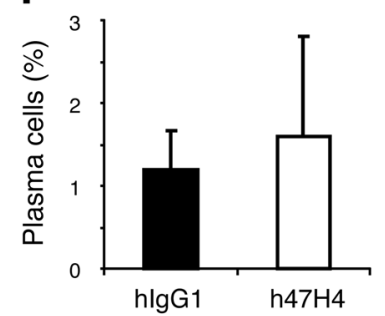

Figure 8

Humanized M1'-specific antibody induces apoptosis of membrane IgE-transfected Daudi cells and specifically reduces IgE in an atopic human PBMC-SCID model. (A) Humanized M1'-specific 47H4 antibody (h47H4) induced apoptosis of human membrane IgE-transfected Daudi cells. (B) Experimental design for atopic human PBMC-SCID model. Sublethally irradiated SCID-beige mice $(n=11-12$ per group) were injected with $10^{8}$ PBMCs from an atopic human donor. Mice were treated on days 2, 3, and 4 with $100 \mathrm{ng}$ recombinant human IL-4 and on days 0 and 3 with $100 \mu \mathrm{g}$ each of anti-human IFN- $\gamma$ and anti-human IL-12 neutralizing antibodies. Then, $300 \mu \mathrm{g}$ humanized M1'-specific $47 \mathrm{H} 4$ antibody or control hlgG1 antibody was delivered 3 times a week, starting on day 0 . Treatment with humanized M1'-specific $47 \mathrm{H} 4$ antibody reduced (C) total serum human IgE levels and (D) the number of splenic human IgE-producing plasma cells, but did not affect (E) total human IgM levels or (F) the frequency of total $\mathrm{CD} 38^{+} \mathrm{PC}+$ splenic plasma cells. Results are mean $\pm \mathrm{SD}$. ${ }^{*} P<0.0001$ (Dunnett's test).

tion Kit I (BD Biosciences). Data was analyzed using FlowJo FACs analysis software (Tree Star). Please see the Supplemental Methods for description of the Daudi cell apoptosis crosslinking assay, the U266 in vitro apoptosis assay, and Daudi cell and U266 in vitro calcium flux assays.

In vitro splenocyte IgE switch cultures. B cells were purified from human M1' knockin mouse spleens by negative selection, using magnetic bead separation, according to the manufacturer's instructions (Miltenyi Biotec). Then, $2 \times 10^{6}$ purified B cells were cultured in $2 \mathrm{ml}$ complete media (RPMI, $10 \% \mathrm{FBS}$, penicillin/streptomycin, $50 \mu \mathrm{M} \beta$-ME) with recombinant mouse IL-4 (100 ng/ml) and anti-mouse CD40 antibody (10 $\mu \mathrm{g} / \mathrm{ml})$ for 4 days. On day 4, supernatants were harvested for IgE measurement and cells were harvested for FACS analysis. Data was analyzed using FlowJo FACs analysis software (Tree Star).

TNP-OVA immunization (primary and secondary/memory responses). Human M1' knockin mice were immunized intraperitoneally with $100 \mu \mathrm{g}$ TNP-OVA (Biosearch Technologies) in $2 \mathrm{mg}$ aluminum hydroxide in $100 \mu \mathrm{l}$ saline on day 0 . For secondary/memory responses, mice that had undergone primary immunization were challenged intraperitoneally on day 28 with $100 \mu \mathrm{g}$ TNP-OVA. Mice were treated intraperitoneally with $10 \mathrm{mg} / \mathrm{kg} \mathrm{M1}$ '-specific antibody or control antibody in saline 3 times per week, between days 0 and 28 , to prevent the primary $\operatorname{IgE}$ response or with $10 \mathrm{mg} / \mathrm{kg} \mathrm{M1}$ '-specific antibody or control antibody, between days 28 and 49, to prevent the secondary/memory response.

N. brasiliensis infection. L3 larvae of N. brasiliensis (R. Locksley, UCSF, San Francisco, California, USA) were isolated from the feces of infected C57BL/6 mice (The Jackson Laboratory). Human M1' knockin mice were infected with $500 \mathrm{~N}$. brasiliensis larvae in $200 \mu \mathrm{l}$ saline and were treated intraperitoneally with $10 \mathrm{mg} / \mathrm{kg} \mathrm{M1}$-specific antibody or control antibody in saline either 3 times per week, starting on day 0 for prophylactic treat- ment, or 3 times per week, starting on day 11 for therapeutic treatment. To quantitate IgE-producing plasma cells and total plasma cells, mesenteric lymph nodes were harvested from mice at day 21 after infection.

Mouse allergic asthma model. Human M1' knockin mice were immunized intraperitoneally with $50 \mu \mathrm{g}$ TNP-OVA in $2 \mathrm{mg}$ aluminum hydroxide in $100 \mu \mathrm{l}$ saline on day 0 and challenged with aerosol TNP-OVA ( $1 \%$ in saline) daily for 7 consecutive days, starting on day 35 . Mice were treated intraperitoneally with $100 \mu \mathrm{g} \mathrm{M1}$ '-specific antibody or control antibody in $100 \mu \mathrm{l}$ saline daily for 7 days, starting on day 38. To quantitate IgE-producing plasma cells and total plasma cells, spleens were harvested from mice at day 63 .

Human PBMC-SCID model. Human blood donors were screened for high serum IgE levels, and 2 donors with 1,696 and 1,152 ng/ml serum IgE were selected to provide cells after giving informed written consent. Use of human cells for these studies was approved by the Genentech Institutional Animal Care and Use Committee. Human PBMCs were isolated by leukopheresis and Ficoll density gradient (GE Healthcare), and $10^{8}$ PBMCs were injected intraperitoneally in $100 \mu \mathrm{l}$ saline into SCID-beige mice (Charles River) that had been irradiated sublethally with $3.5 \mathrm{~Gy}$ from a cesium 137 source. Mice were treated with $110 \mathrm{mg} / \mathrm{l}$ polymyxin $\mathrm{B}$ and $1.1 \mathrm{~g} / \mathrm{l}$ neomycin in their drinking water throughout the course of the study. In order to promote IgE production, mice were given intraperitoneal injections of $100 \mu \mathrm{g}$ each of anti-human IFN- $\gamma$ and antihuman IL-12 antibodies (BD Biosciences) in saline on days 0 and 3 and 100 ng of recombinant human IL-4 (R\&D Systems) in saline on days 2, 3 , and 4. Mice were treated intraperitoneally with $300 \mu \mathrm{g} \mathrm{M1}$-specific antibody or control antibodies in saline 3 times per week (approximately every 3 days), starting on day 0 until the end of the study (typically 8-9 days). To quantitate IgE-producing plasma cells and total plasma cells, spleens were harvested at takedown. 
A

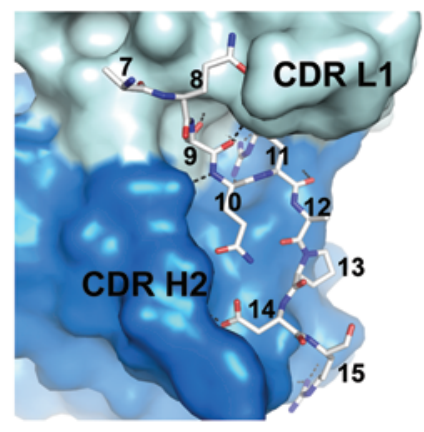

B



c

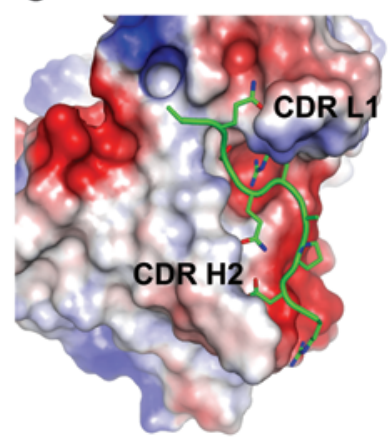

Figure 9

Crystal structure of humanized M1'-specific 47H4 antibody Fab in complex with M1'-derived peptide. (A) The crystal structure of the humanized M1'-specific 47H4 antibody Fab (space filling mode; heavy chain is shown as blue, light chain is shown as gray) in complex with an M1'-derived peptide (stick model, Ac-S6AQSQRAPDRVLCHSGQQQGLPRAAGGSVPHPRCH40-OOH) shows hydrogen bonds (dotted lines) between the h47H4 Fab and the M1' peptide and burial of an arginine side chain from the M1' peptide (Arg 11) in a central deep pocket in the h47H4 Fab. Numbers correspond to amino acid residues in the entire M1' sequence. (B) The arginine binding pocket is formed by CDRs L1 (magenta), L3 (red), and H3 (purple), but CDR H2 (yellow) makes more contacts with the peptide than any other CDR. Amino acid side chains in the Fab that make important contacts with the peptide are shown as stick representations. (C) Four antibody aspartic acid residues in the Fab peptide-binding region combine to create a net negative electrostatic potential (red), which is complementary to the positive charges from M1' peptide arginine side chains. $H$, heavy chain; $L$, light chain.

Humanization of M1'-specific antibody. Murine M1'-specific antibody (clone 47H4) variable light and variable heavy $(\mathrm{VH})$ domains were amplified using RT-PCR and degenerate primers to the heavy and light chains. The sequence of the primers used to clone the heavy and light chain variable regions are as follows, where $\mathrm{Y}$ indicates either $\mathrm{C}$ or $\mathrm{T}$; $\mathrm{B}$ indicates $\mathrm{C}, \mathrm{G}$, or $\mathrm{T}$; $\mathrm{R}$ indicates either $\mathrm{A}$ or $\mathrm{G}$; $\mathrm{W}$ indicates either $\mathrm{A}$ or $\mathrm{T}$; and $\mathrm{M}$ indicates either A or C: heavy chain forward primer, 5'-GATCGACGTACGCTGAGGTRAAGYTGGTGAARTCTGG-3'; heavy chain reverse primer, 5'-CTGGWCAGGGMTCCAGAGTTCCA-3'; light chain forward primer, 5 '-GATCGATATCGTGYTGACBCARACTCCACT-3'; light chain reverse primer, 5'-GCTGTAGGTGCTGTCTTTGCT-3'. Hypervariable regions from murine 47H4 were grafted into the human KI and VH subgroup III consensus acceptor frameworks, and point mutations were introduced to avoid potential manufacturing issues arising from potential deamidation/isoaspartic formation and methionine oxidation.

Radioligand cell binding analysis. Iodinated M1'-specific antibody was mixed with 2-fold dilutions of unlabeled $\mathrm{M} 1$ '-specific antibody and added to approximately $2.5 \times 10^{5}$ human membrane IgE-transfected Daudi cells in base media, with $10 \mathrm{mM}$ HEPES, pH 7.4, $2 \% \mathrm{FBS}$, and $40 \mu \mathrm{g} / \mathrm{ml}$ human IgG. The antibody/cell mixture was incubated at $4{ }^{\circ} \mathrm{C}$ for 4 hours while shaking and then collected and filtered using a Millipore Multiscreen filtration plate. The Durapore membrane filters were counted for 10 minutes using Perkin Elmer Wizard 1470 Auto Gamma Counter.

Crystallography. Humanized 47H4 M1'-specific antibody Fab in $0.15 \mathrm{M}$ $\mathrm{NaCl}, 10 \mathrm{mM}$ MOPS, $\mathrm{pH} 7.3$, at $4.5 \mathrm{mg} / \mathrm{ml}$ and $5 \mathrm{mg} \mathrm{M1}$ ' peptide (35 amino acids, 10 -fold molar excess) were mixed and subjected to crystallization trials, using a sparse matrix of precipitants in a sitting drop format. Optimized crystals grew from a 1:1 mixture, with 20\% w/v PEG 3350, $0.2 \mathrm{M}$ ammonium sulfate, and $0.1 \mathrm{M}$ Bis-TRIS, $\mathrm{pH} 5.7$, and were cryoprotected using $20 \% \mathrm{v} / \mathrm{v}$ glycerol, plus reservoir during immersion into liquid nitrogen. Data in space group $\mathrm{P} 2{ }_{1} 2_{1} 2_{1}$, with $4 \mathrm{Fab} /$ peptide complexes in the asymmetric unit extending to $4 \AA$ resolution, were collected on a Mar345 scanner and Rigaku 007. The structure was solved by molecular replacement, using Phaser (66) and separate variable and constant regions of a humanized anti-HER2 Fab (67) as search probes. Subsequent data, extending to $2.4 \AA$, were collected at beamline ID29 of the ESRF, using the services of MXpress. Data were reduced using HKL2000 (68) and CCP4 (69). Electron density evidence for 6 to 8 amino acids of the M1' peptide was apparent in all 4 copies, after some refinement at $2.4 \AA$ and near complete building of the CDR loops. The proper sequence was identified using principally the shape of electron density for residues Arg11 and Pro13 and the overall pattern of side chain sizes. Refinement was performed with REFMAC5 (70) and included TLS applied in 8 groups (see Supplemental Table 1). Coordinates and structure factors have been deposited in the RCSB Protein Data Bank (http://www.rcsb.org), under accession code 3HR5.

Serum immunoglobulin assays. For measurement of TNP-OVA-specific mouse IgE and IgG1 in serum, 384-well MaxiSorp plates (Nunc) were coated for $12-18$ hours at $4{ }^{\circ} \mathrm{C}$ with $0.5 \mu \mathrm{g} / \mathrm{ml}$ TNP-OVA (Biosearch Technologies) in a carbonate buffer. Plates were washed, blocked with PBS/0.5\% BSA for 1-2 hours at room temperature, washed again, and incubated with serum samples or standards for 2 hours at room temperature. Samples were diluted in PBS, 0.5\% BSA, 0.05\% Tween-20, and $0.01 \%$ Proclin 300 (Supelco). TNP-OVA-specific mouse IgE or IgG1 levels were quantitated using biotinylated rat anti-mouse IgE or IgG1 antibody (BD Biosciences). For measurement of human IgE, 384-well MaxiSorp plates (Nunc) were coated overnight at $4^{\circ} \mathrm{C}$ with $1 \mu \mathrm{g} / \mathrm{ml}$ monoclonal antihuman IgE antibody (MAE11, Genentech) in a carbonate buffer. Plates were washed, blocked with PBS/0.5\% BSA for 1 hour at room temperature, washed again, and incubated with serum samples or standards for 1 hour at room temperature. Samples were diluted in PBS, $0.5 \%$ BSA, $0.05 \%$ polysorbate 20, 10 parts per million Proclin 300 (Supelco), $0.25 \%$ CHAPS, $0.2 \%$ bovine $\gamma$ globulins (Biocell), and $5 \mathrm{mM}$ EDTA. IgE was quantitated using peroxidase-labeled goat anti-human IgE antibody (Kirkegaard \& Perry Laboratories). For measurement of human IgM, 384-well MaxiSorp plates (Nunc) were coated overnight at $4^{\circ} \mathrm{C}$ with $0.5 \mu \mathrm{g} / \mathrm{ml}$ monoclonal mouse anti-human IgM antibody (BD Pharmingen) in a carbonate buffer. Plates were washed, blocked with PBS $/ 0.5 \%$ BSA for 1 hour at room temperature, washed again, and incubated with serum samples or standards for 1 hour at room temperature. IgM was quantitated using biotin-conjugated mouse anti-human IgM antibody (BD Pharmingen) and SA-HRP (GE Healthcare). The minimum quantifiable concentration of human IgM in the mouse serum samples was $156 \mathrm{ng} / \mathrm{ml}$. 
IgE ELISpot assays. For human IgE ELISpot, plates (Millipore) were coated with anti-human IgE antibody (AXXORA) overnight at $4^{\circ} \mathrm{C}$. Plates were then washed, blocked with PBS $/ 0.5 \%$ BSA for $0.5-1$ hours at $37^{\circ} \mathrm{C}$, washed again, and incubated with splenocytes or U266 control cells (ATCC) overnight at $37^{\circ} \mathrm{C}$ in RPMI $1640 / 10 \% \mathrm{FBS}$. Human IgE levels were quantitated using alkaline phosphatase-conjugated anti-human IgE antibody (Sigma-Aldrich). ELISpots were either counted manually, or plates were sent to BD Biosciences for counting. Mouse IgE ELISpot was performed with anti-mouse IgE capture and biotinylated anti-mouse IgE detection antibodies (BD OptEIA $\mathrm{mIgE}$ ), and TNP-OVA-specific IgE ELISpot was performed with $10 \mu \mathrm{g} / \mathrm{ml}$ TNP-OVA (Biosearch Technologies) as the capture reagent and biotinylated anti-mouse IgE detection antibody (BD OptEIA mIgE). The mouse A20 B cell line TIB-208 (ATCC) was used as a negative control and the anti-TNP mouse IgE cell line TIB-141 (ATCC) was used as a positive control.

Plasma cell flow cytometry. Human plasma cells were detected in spleens harvested from SCID mice reconstituted with human PBMC (hu-SCID mice), using anti-human CD38 (BD Biosciences) and anti-human plasma cell (anti-human PC; Dakocytomation) antibodies. Mouse plasma cells from spleen or lymph nodes were detected using anti-mouse CD138 antibodies (BD Biosciences).

Statistics. In vivo ELISA, ELISpot, and FACS cell population percentage data are expressed as the mean \pm SD. $P$ values were calculated using JMP statistics software (SAS). Dunnett's test was used to compare group means where all test groups are tested against a reference group. Each Pair Student's $t$ test was used to compare each group pair using Student's $t$ test. A Bonferroni correction was then applied to adjust the $P$ values of the Each Pair Student's $t$ test to account for pairwise comparisons. $P$ values of less than 0.05 were considered to be significant.

\section{Acknowledgments}

The authors would like to thank Jiabing Ding, Merone RooseGirma, Michele Bauer, and Melanie Domeyer for assistance with generation and maintenance of the M1' knockin mouse colony; Laurie Gilmour and Jim Cupp for assistance with flow cytometry; and Andrew Chan, John Monroe, and Flavius Martin for helpful discussions.

Received for publication June 10, 2009, and accepted in revised form March 17, 2010.

Address correspondence to: Lawren C. Wu, Department of Immunology, Genentech Inc., 1 DNA Way, MS 34, South San Francisco, California 94080, USA. Phone: 650.225.1548; Fax: 650.742.1521; E-mail: lawren@gene.com.
1. Galli SJ, Tsai M, Piliponsky AM. The development of allergic inflammation. Nature. 2008;454(7203):445-454.

2. Gould HJ, Sutton BJ. IgE in allergy and asthma today. Nat Rev Immunol. 2008;8(3):205-217.

3. Gould HJ, et al. The biology of IgE and the basis of allergic disease. Annu Rev Immunol. 2003;21:579-628.

4. Oettgen HC, Geha RS. IgE regulation and roles in asthma pathogenesis. J Allergy Clin Immunol. 2001;107(3):429-440

5. Kawakami T, Galli SJ. Regulation of mast-cell and basophil function and survival by IgE. Nat Rev Immunol. 2002;2(10):773-786.

6. Kawakami T, Kitaura J. Mast cell survival and activation by $\operatorname{IgE}$ in the absence of antigen: a consideration of the biologic mechanisms and relevance. J Immunol. 2005;175(7):4167-4173.

7. Berger WE. What is new in antiimmunoglobulin E asthma therapy. Allergy Asthma Proc. 2005;26(6):428-434.

8. Chang TW, Wu PC, Hsu CL, Hung AF. Anti-IgE antibodies for the treatment of IgE-mediated allergic diseases. Adv Immunol. 2007;93:63-119.

9. Poole JA, Matangkasombut P, Rosenwasser LJ. Targeting the IgE molecule in allergic and asthmatic diseases: review of the IgE molecule and clinical efficacy. J Allergy Clin Immunol. 2005;115(3):S376-385.

10. Beck LA, Marcotte GV, MacGlashan D, Togias A, Saini S. Omalizumab-induced reductions in mast cell Fce psilon RI expression and function. J Allergy Clin Immunol. 2004;114(3):527-530.

11. Lin $\mathrm{H}$, et al. Omalizumab rapidly decreases nasal allergic response and FcepsilonRI on basophils. J Allergy Clin Immunol. 2004;113(2):297-302.

12. MacGlashan D Jr, et al. In vitro regulation of FcepsilonRIalpha expression on human basophils by IgE antibody. Blood. 1998;91(5):1633-1643.

13. MacGlashan DW Jr, et al. Down-regulation of Fc(epsilon)RI expression on human basophils during in vivo treatment of atopic patients with antiIgE antibody. J Immunol. 1997;158(3):1438-1445.

14. Saini SS, et al. Down-regulation of human basophil $\mathrm{IgE}$ and FC epsilon RI alpha surface densities and mediator release by anti-IgE-infusions is reversible in vitro and in vivo. J Immunol. 1999;162(9):5624-5630.

15. Corne J, et al. The effect of intravenous administration of a chimeric anti-IgE antibody on serum IgE levels in atopic subjects: efficacy, safety, and pharmacokinetics. J Clin Invest. 1997;99(5):879-887.

16. Milgrom $\mathrm{H}$, et al. Treatment of allergic asthma with monoclonal anti-IgE antibody. rhuMAb-E25 Study Group. NEngl J Med. 1999;341(26):1966-1973.

17. Andjelic S, Liou HC. Antigen receptor-induced B lymphocyte apoptosis mediated via a protease of the caspase family. Eur J Immunol. 1998;28(2):570-581.

18. Chung JB, Silverman M, Monroe JG. Transitional B cells: step by step towards immune competence. Trends Immunol. 2003;24(6):343-349.

19. Cooper MD, Kearney JF, Gathings WE, Lawton AR. Effects of anti-Ig antibodies on the development and differentiation of B cells. Immunol Rev. 1980;52:29-53.

20. Eldering E, VanLier RA. B-cell antigen receptorinduced apoptosis: looking for clues. Immunol Lett. 2005;96(2):187-194.

21. Finkelman FD, Holmes JM, Dukhanina OI, Morris SC. Cross-linking of membrane immunoglobulin $\mathrm{D}$, in the absence of $\mathrm{T}$ cell help, kills mature B cells in vivo. J Exp Med. 1995;181(2):515-525.

22. Gause A, Yoshida N, Kappen C, Rajewsky K. In vivo generation and function of $\mathrm{B}$ cells in the presence of a monoclonal anti-IgM antibody: implications for B cell tolerance. Eur J Immunol. 1987;17(7):981-990.

23. Gold MR. To make antibodies or not: signaling by the B-cell antigen receptor. Trends Pharmacol Sci. 2002;23(7):316-324.

24. Goodyear CS, Silverman GJ. Death by a B cell superantigen: In vivo $\mathrm{VH}$-targeted apoptotic supraclonal B cell deletion by a Staphylococcal Toxin. J Exp Med. 2003;197(9):1125-1139.

25. Goodyear CS, Silverman GJ. Staphylococcal toxin induced preferential and prolonged in vivo deletion of innate-like B lymphocytes. Proc Natl Acad Sci US A. 2004;101(31):11392-11397.

26. Healy JI, Goodnow CC. Positive versus negative signaling by lymphocyte antigen receptors. Annu Rev Immunol. 1998;16:645-670.

27. Niiro H, Clark EA. Regulation of B-cell fate by antigen-receptor signals. Nat Rev Immunol. 2002;2(12):945-956.

28. Wardemann H, Nussenzweig MC. B-cell self-tolerance in humans. Adv Immunol. 2007;95:83-110.

29. Chen SS, Katz DH. IgE class-restricted tolerance induced by neonatal administration of soluble or cell-bound IgE. J Exp Med. 1983;157(2):772-788.
30. Haba S, Nisonoff A. Inhibition of IgE synthesis by anti-IgE: role in long-term inhibition of IgE synthesis by neonatally administered soluble IgE. Proc Natl Acad Sci U S A. 1990;87(9):3363-3367.

31. Haba S, Nisonoff A. Effects of syngeneic anti-IgE antibodies on the development of IgE memory and on the secondary IgE response. J Immunol. 1994;152(1):51-57.

32. Feichtner $S$, et al. Targeting the extracellular membrane-proximal domain of membrane-bound IgE by passive immunization blocks IgE synthesis in vivo. J Immunol. 2008;180(8):5499-5505.

33. Batista FD, Efremov DG, Burrone OR. Characterization and expression of alternatively spliced IgE heavy chain transcripts produced by peripheral blood lymphocytes. JImmunol. 1995;154(1):209-218.

34. Batista FD, Efremov DG, Tkach T, Burrone OR. Characterization of the human immunoglobulin epsilon mRNAs and their polyadenylation sites. Nucleic Acids Res. 1995;23(23):4805-4811.

35. Davis FM, Gossett LA, Chang TW. An epitope on membrane-bound but not secreted IgE: implications in isotype-specific regulation. Biotechnology (NY). 1991;9(1):53-56.

36. Diaz-Sanchez D, Zhang K, Nutman TB, Saxon A. Differential regulation of alternative 3 ' splicing of epsilon messenger RNA variants. J Immunol. 1995;155(4):1930-1941.

37. Hellman L. Characterization of four novel epsilon chain mRNA and a comparative analysis of genes for immunoglobulin $\mathrm{E}$ in rodents and man. Eur J Immunol. 1993;23(1):159-167.

38. Ishida N, Ueda S, Hayashida H, Miyata T, Honjo T. The nucleotide sequence of the mouse immunoglobulin epsilon gene: comparison with the human epsilon gene sequence. EMBOJ. 1982;1(9):1117-1123.

39. Peng C, Davis FM, Sun LK, Liou RS, Kim YW, Chang TW. A new isoform of human membranebound IgE. J Immunol. 1992;148(1):129-136.

40. Saxon A, Max EE, Diaz-Sanchez D, Zhang K. Alternative RNA of epsilon transcripts produces mRNAs encoding two membrane and four secreted IgE isoforms. Int Arch Allergy Immunol. 1995;107(1-3):45-47.

41. Zhang K, Saxon A, Max EE. Two unusual forms of human immunoglobulin $\mathrm{E}$ encoded by alternative RNA splicing of epsilon heavy chain membrane exons. J Exp Med. 1992;176(1):233-243. 
42. Haba S, Ovary Z, Nisonoff A. Clearance of IgE from serum of normal and hybridoma-bearing mice. J Immunol. 1985;134(5):3291-3297.

43. Hirano T, Hom C, Ovary Z. Half-life of murine IgE antibodies in the mouse. Int Arch Allergy Appl Immunol. 1983;71(2):182-184.

44. Katona IM, Urban JF Jr, Scher I, Kanellopoulos-Langevin C, Finkelman FD. Induction of an IgE response in mice by Nippostrongylus brasiliensis: characterization of lymphoid cells with intracytoplasmic or surface IgE. J Immunol. 1983;130(1):350-356.

45. Ota T, Aoki-Ota M, Duong BH, Nemazee D. Suppression of IgE B cells and IgE binding to Fc(epsilon)RI by gene therapy with single-chain anti-IgE. J Immunol. 2009;182(12):8110-8117.

46. Chiang EY, et al. Targeted depletion of lymphotoxinalpha-expressing TH1 and TH17 cells inhibits autoimmune disease. Nat Med. 2009;15(7):766-773.

47. Shields RL, et al. High resolution mapping of the binding site on human IgG1 for Fc gamma RI, FC gamma RII, Fc gamma RIII, and FcRn and design of IgG1 variants with improved binding to the FC gamma R. J Biol Chem. 2001;276(9):6591-6604.

48. Gong Q, et al. Importance of cellular microenvironment and circulatory dynamics in B cell immunotherapy. JImmunol. 2005;174(2):817-826.

49. Uchida J, et al. The innate mononuclear phagocyte network depletes B lymphocytes through Fc receptor-dependent mechanisms during anti-CD20 antibody immunotherapy. J Exp Med. 2004;199(12):1659-1669.

50. Erazo A, et al. Unique maturation program of the IgE response in vivo. Immunity. 2007;26(2):191-203.

51. Heusser CH, Wagner K, Brinkmann V, Severinson E, Blaser K. Establishment of a memory in vitro murine IgE response to benzylpenicillin and its resistance to suppression by anti-IL-4 antibody. Int Arch Allergy Appl Immunol. 1989;90(suppl 1):45-50.
52. Kolbe L, Heusser C, Kolsch E. Antigen dosedependent regulation of B epsilon-memory cell expression. Int Arch Allergy Appl Immunol. 1991; 95(2-3):202-206.

53. Le Gros G, et al. The development of $\operatorname{IgE}+$ memory $\mathrm{B}$ cells following primary IgE immune responses. Eur IImmunol. 1996;26(12):3042-3047.

54. Sudowe S, Rademaekers A, Kolsch E. Antigen dosedependent predominance of either direct or sequential switch in IgE antibody responses. Immunology. 1997;91(3):464-472.

55. Sudowe S, Specht C, Kolbe L, Kolsch E. In situ dormancy of B lymphocytes programmed for an $\operatorname{IgE}$ antibody response and their sudden release from unresponsiveness under in vitro conditions. Int Immunol. 1995;7(11):1799-1807.

56. Takahama H, Ovary Z, Furusawa S. Murine IgG1 and IgE memory B cells. Cell Immunol. 1994;157(2):369-380.

57. Brinkmann V, Muller S, Heusser $\mathrm{CH}$. T cell dependent differentiation of human B cells: direct switch from IgM to IgE, and sequential switch from IgM via IgG to IgA production. Mol Immunol. 1992;29(10):1159-1164.

58. Jung S, Siebenkotten G, Radbruch A. Frequency of immunoglobulin $\mathrm{E}$ class switching is autonomously determined and independent of prior switching to other classes. J Exp Med. 1994;179(6):2023-2026.

59. Mandler R, Finkelman FD, Levine AD, Snapper CM. IL-4 induction of IgE class switching by lipopolysaccharide-activated murine B cells occurs predominantly through sequential switching. J Immunol. 1993;150(2):407-418.

60. Shapira SK, et al. Deletional switch recombination occurs in interleukin-4-induced isotype switching to IgE expression by human B cells. Proc Natl Acad Sci US A. 1991;88(17):7528-7532.

61. Shapira SK, Vercelli D, Jabara HH, Fu SM, Geha
RS. Molecular analysis of the induction of immunoglobulin $\mathrm{E}$ synthesis in human B cells by interleukin 4 and engagement of CD40 antigen. $J$ Exp Med. 1992;175(1):289-292.

62. Siebenkotten G, Esser C, Wabl M, Radbruch A. The murine IgG1/IgEclass switch program. EurJImmunol. 1992;22(7):1827-1834.

63. Vercelli D. Regulation of IgE synthesis. Allergy Proc. 1993;14(6):413-416.

64. Yoshida K, Matsuoka M, Usuda S, Mori A, Ishizaka $\mathrm{K}$, Sakano H. Immunoglobulin switch circular DNA in the mouse infected with Nippostrongylus brasiliensis: evidence for successive class switching from mu to epsilon via gamma 1. Proc Natl Acad Sci US A. 1990;87(20):7829-7833.

65. Achatz-Straussberger G, et al. Limited humoral immunoglobulin E memory influences serum immunoglobulin E levels in blood. Clin Exp Allergy. 2009;39(9):1307-1313.

66. Read RJ. Pushing the boundaries of molecular replacement with maximum likelihood. Acta Crystallogr D Biol Crystallogr. 2001;57(pt 10):1373-1382.

67. Eigenbrot C, Randal M, Presta L, Carter P, Kossiakoff AA. X-ray structures of the antigen-binding domains from three variants of humanized anti-p185HER2 antibody 4D5 and comparison with molecular modeling. J Mol Biol. 1993;229(4):969-995.

68. Otwinowski Z, Minor W. Processing of X-ray diffraction data collected in oscillation mode. Methods Enzymol. 1997;276:307-326.

69. [No authors listed]. Collaborative Computational Project, Number 4. The CCP4 Suite: Programs for protein crystallography. Acta Crystallogr D Biol Crystallogr. 1994;50(pt 5):760-763.

70. Murshudov GN, Vagin AA, Dodson EJ. Refinement of macromolecular structures by the maximumlikelihood method. Acta Crystallogr D Biol Crystal$\log$. 1997;53(pt 3):240-255. 